\title{
THE ROLE OF THE INTERNATIONAL TRANSPORT IN FOREIGN TRADE REALIZATION
}

\author{
Antoaneta Kirova \\ "Todor Kableshkov " University of Transport, Sofia, Bulgaria
}

\section{(C) MESTE NGO}

JEL category: F4, L9, L92, N7, O18, R4, R41

\begin{abstract}
The transportation costs comprise the basic share of the total costs in international tradeand highly influence the prices of goods. In a great number of cases, the trading considerations require transportation costs higher than the value of goods. The increasing trade flows and the aim to cut the delivery terms which aids the flexibility of the different companiesare pressing demands over the modes of the international transport.

The economic efficiency could be raised through increasing of the competitive advantages. Besides, the international labor specialization, the access to a greater variety of material and non-material products allowing more efficient production decisions, economies of scope and scale, etc. bring forward substantial requirements towards the new transport technologies and the modes of the international transport as a whole. Another tendency brings forward the increased pollution of the environment due to the high share of the road transport and air transport at short and medium distances.

On the other hand, the high competitiveness of the road transport at short and medium distances presents a good reason for the consumer choice, hence according to the statistical data, it is the most widely applied in the realizationof Bulgarian foreign trade. Another reason is that the partners from EU form a dominant share in the foreign trade of Bulgaria.

The higher prices of transport by air are still limiting its applicationin the cargo exchange, in comparison to the land transport. There are still options and opportunities for increasing the role of maritime transport and transport by inner waterways.
\end{abstract}

Key words: international turnover of goods, international transport, transport policy, SITC

\section{INTRODUCTION}

The shift towards greater interdependence of the world's economies has an enormous impact on

Address of the author:

Antoaneta Kirova

彗= toni.kirova@gmail.com the demand for transportation services. Production of labor intensive component parts has shifted to countries with lower cost labor markets requiring further transportation for assembly of the manufactured product. This decentralized manufacturing and assembly, involving multiple locations has increased both transportation and 
information management requirements. Shippers require global transportation coverage. Global markets increase the importance of international standards for transportation equipment and documentation.

Distribution of goods has become a major element of global trade, as it increases the competitiveness of regions with developed logistics. This kind of competitiveness is often identified with the competitiveness of other segments of the supply chain, for example, resources 'producing, manufacturing and retail. The existence of public and private interests leads to priorities in the allocation of investments in various infrastructure activities related to logistics and management of supply chains. Thus logistic zones disposing of intermodal terminals are created, for example port facilities and railway stations. The freight transportation services are increasingly outsourced and a lot of companies divide transport and storage activities from their core business. On the other hand, firms reduce the number of transport providers to optimize their costs and improve service. Performance of logistics activities provides opportunities for major transport companies to take control of more segments of the supply chain. Mergers and acquisitions create major logistic operators controlling the supply chain (i.e. megacarriers). The role of IT (for controlling the transport and related processes) and intermodal integration (controlling material flows) lead to the intensified supply chain operations through transactions and information exchange. Ultimately, logistics is the management of product flows in time and space and globalization puts additional pressure through the necessity of information flows management (order processing, booking transport capacity, routing, etc.)

The costs of transportation are a major part of the general logistic costs and highly influence the prices of commodities. There are numerous cases where commercial considerations allow for higher rate of the transportation costs, especially if the product life cycle is concerned. On the other hand, the globalization of the international trade and the increasing amount of internationally exchanges goods requires efforts to be made towards shortening the delivery times which brings forward a bigger flexibility for the competing companies. As a result the occupation of the international transport increases bearing in mind the possibility of substitution of one mode of transport with another, while delivering goods at their destination.

There are two basic tendencies influenced by the increased volumes of goods carried in the global world:

- The first one is improving economic efficiency through stronger competition. This is due to the international labour specialization, bringing forward competences, the access to greater variety of products and services, the existing opportunities for efficient production decisions, economies of scale, etc.;

- The second one is related to the increasing pollution of the air and the environment, due to the comparatively high rate of road transport and air transport at short distances.

The foreign trade of Bulgaria is among the examples for a considerable amount of freight carried by road, the main reason for that being establishing partnerships within EU region and other parts of Europe. Another unexplored mode of transport due to the unfavourable development of infrastructure is railway transport. Though suitable for medium distances it is still underestimated by the clients and they prefer road transport. The opportunities of waterborne transport are either neglected or underdeveloped, which should be reconsidered within the national transport policy. The participation of air transport is not stable due to different factors, mainly economic.

\section{CURRENT STATE OF INTERNATIONAL TRANSPORT IN EU AND OECD CUNTRIES}

The product trade between the EU countries in 2011 amounts to 2804131 million EUR, which almost doubles the value exported to non-EU countries, thus indicating the importance of the internal EU market for the member states, with the exception of Great Britain. The correlation in the freight volumes between the EU countries and out of the EU region is a result of their historic connections as well as their geographic position. The highest trade rates within the EU belong to Luxemburg, Slovakia and the Czech Republic (amounting at $80 \%$ altogether), while there is a reduction of about $51,2 \%$ for Greece and almost 
Kirova A.The role of the international transport in foreign trade realization

MEST Journal Vol. 2 No. 2 pp. 74-85

$49,4 \%$ for the UK. Measuring the incoming and outgoing traffic levels, the greatest increase within the EC have reported Estonia (33,5\%), Latvia $(32,3 \%)$, Lithuania (28,2\%) and Bulgaria (27.7\%), while in Greece and Cyprus the decrease is accordingly $2.4 \%$ and $0.3 \%$. (Data retrieved and analysed from: (Euroepan Commission, 2014))

Table 1 Foreign trade within EU region

\begin{tabular}{|c|c|c|c|c|c|c|}
\hline & \multicolumn{2}{|c|}{ Dispatches } & \multicolumn{2}{|c|}{ Arrivals } & \multicolumn{2}{|c|}{ Balance } \\
\hline & 2010 & 2011 & 2010 & 2011 & 2010 & 2011 \\
\hline EU-27 & 2540.7 & 2804.1 & 2468.9 & 2728.1 & 71.8 & 76.0 \\
\hline Belgium & 225.2 & 246.8 & 205.5 & 226.5 & 19.6 & 20.3 \\
\hline Bulgaria & 9.5 & 12.6 & 11.3 & 13.8 & -1.8 & -1.2 \\
\hline Czech Republic & 84.3 & 96.7 & 71.6 & 81.1 & 12.7 & 15.7 \\
\hline Denmark & 48.4 & 53.5 & 45.1 & 50.0 & 3.2 & 3.6 \\
\hline Germany & 570.9 & 627.2 & 502.9 & 572.6 & 68.0 & 54.6 \\
\hline Estonia & 6.0 & 8.0 & 7.4 & 9.9 & -1.4 & -1.9 \\
\hline Ireland & 51.0 & 53.0 & 30.6 & 33.3 & 20.4 & 19.7 \\
\hline Greece & 10.2 & 11.3 & 24.6 & 22.7 & -14.4 & -11.4 \\
\hline Spain & 131.8 & 146.4 & 145.6 & 153.8 & -13.8 & -7.3 \\
\hline France & 240.4 & 261.4 & 314.0 & 346.5 & -73.6 & -85.1 \\
\hline Italy & 193.5 & 210.5 & 201.4 & 213.5 & -7.9 & -3.0 \\
\hline Cyprus & 0.7 & 0.9 & 4.5 & 4.3 & -3.8 & -3.4 \\
\hline Latvia & 4.8 & 6.2 & 6.7 & 9.1 & -1.9 & -2.8 \\
\hline Lithuania & 9.5 & 12.4 & 10.0 & 12.6 & -0.4 & -0.3 \\
\hline Luxembourg & 12.5 & 12.7 & 15.2 & 16.8 & -2.7 & -4.1 \\
\hline Hungary & 55.6 & 61.2 & 45.0 & 51.2 & 10.6 & 10.1 \\
\hline Malta & 1.1 & 1.3 & 2.7 & 3.3 & -1.6 & -2.0 \\
\hline Netherlands & 334.4 & 368.2 & 181.4 & 199.8 & 153.0 & 168.5 \\
\hline Austria & 82.0 & 90.2 & 92.9 & 105.4 & -10.9 & -15.2 \\
\hline Poland & 95.3 & 104.7 & 95.1 & 103.6 & 0.3 & 1.2 \\
\hline Portugal & 27.6 & 31.4 & 43.2 & 42.1 & -15.6 & -10.7 \\
\hline Romania & 26.9 & 32.0 & 34.0 & 39.8 & -7.0 & -7.8 \\
\hline Slovenia & 15.7 & 17.7 & 15.4 & 17.2 & 0.3 & 0.5 \\
\hline Slovakia & 41.1 & 48.2 & 35.3 & 40.2 & 5.8 & 8.1 \\
\hline Finland & 28.5 & 31.5 & 33.3 & 37.2 & -4.8 & -5.6 \\
\hline Sweden & 68.3 & 75.4 & 75.3 & 86.2 & -7.0 & -10.8 \\
\hline United Kingdom & 165.5 & 182.5 & 218.8 & 235.8 & -53.3 & -53.3 \\
\hline
\end{tabular}

Source: Eurostat (online data code: tet00039)

According to the statistical data published in the Global Transport Trends in Perspective of OECD (Statistics Brief, 2013) for 2013, maritime freight, measured in tonnes loaded, grew to 8.7 billion tonnes in 2011 , which is $6 \%$ above the pre-crisis peak in 2008. In tonne-miles, sea cargo grew by $5 \%$, reaching 42.8 billion tonne-miles. Air freight transport rebounded in 2010 and grew 20\% from the previous year to a new high of 172 billion freight tonne-kilometres, but the slowdown in world trade growth and the shifts in the commodity mix favouring sea transport, according to IATA are negatively influencing air transport.
Rail freight grew $3 \%$ in the OECD countries in 2011 , reaching the tonne-km of the pre-crisis levels. The United States, Russia and China account for nearly $80 \%$ of total estimated global rail freight. Preliminary data for rail freight, based on our quarterly statistics, indicate stagnation in Europe and freight volume growth turning negative in the United States.

Road freight in the OECD and EU continue to stagnate below pre-crisis levels. In 2011, the growth in tonne-kilometres slowed down both in the OECD and EU countries, increasing by only $1 \%$. The estimates for the EU area in 2012, 
covering $75 \%$ of the total road tonne-kilometres, indicated a decline of around $4 \%$ for road freight.

Data on freight transport by inland waterways show a rapid recovery in tonne-kilometres in the OECD and the EU in 2010 after the decline in 2009. The growth in volume slowed down in the OECD in $2011(+1 \%)$ and turned negative in the European Union (-4\%). In 2010 and 2011, inland waterway freight volumes grew again rapidly, by $24 \%$ and $16 \%$ respectively. (Data retrieved and analysed from: (OECD, 2014))

In comparison to the other modes of transportation within EC, the road freight transport is continuously growing, the levels remaining high, particularly after the cabotage liberalization in 1993. By the beginning of 1994 the number of the cabotage permits amounts at 30000 , with validity terms within 2 months. After 1995 the registered increase of the permit numbers on an anual basis is about $30 \%$, and the irrevocable entry of road cabotage in enacted from 01.07.1998. The Bulgarian road carriers profit from the cabotage rights in EU countries (Filipova, 2012) since 01.01.2012, with several years delay after the country joined the Community in 2007.

As far as the railway freight transport is concerned, after 2008 when certain success with increasing the freight volumes carried within EU was noticed, the economic crisis turned the trend backwards. Despite this, during the last two decades the share of railways in the general volume of freight carried internationally decreased from $28 \%$ to $15 \%$. Notwithstanding the railway reforms ( 3 packages of measures about the railway transport in EU with a fourth one on the way), the lack of flexibility in the railway system exposed them to the competition of the road transport. The Bulgarian railway reform is further slowed by the predominant share of state ownership in the railway sector, though liberalization took place even before the country joined EU.

Maritime transport has always played an important role in trade between Member States as well in serving foreign trade with third countries. More than $30 \%$ of domestic freight transport in the $\mathrm{EU}$ and about $86 \%$ of foreign trade relations of the Member States are conducted through shipping.
The legal background introducing free market in the field of maritime transport is enacted since the end of 1986 regulates the legal basis of the free market. Moreover, the principle of freedom in providing maritime transport services is realized through:

- Flag carriers of the member states, sailing between these countries;

- Flag carriers of the member states, sailing between these countries and third countries;

- Other free carries, operating between the member states and third countries;

There is a possibility the member states to coordinate their actions about restrictions on imposed upon them towards the free access to overseas trade with third countries. Also there is a procedure against unfair tariff actions adopted by ship-owners from third countries serving international shipping when these actions seriously affect trade to or from the EU.

Transport efficiency has increased significantly because of innovations and improvements in maritime transport. Ports are particularly important in the context since they serve as gateways to international trade through maritime shipping networks. As a result, the transferability of commodities, parts and finished goods has been improved.

The situation in the field of air transport is showing that the major airlines of the European countries (the flag carriers) engage in strategic partnerships with the principal North American carriers and those from other continents. Within an extended period of time, the instruments for international regulation of air transport are primarily focused on solving technical issues rather than on establishment of a competitive open market for transport services. The air traffic between Member States is subject mainly on bilateral agreements.

The modes of transportation described on the previous pages have each developed independently, without great concern to interconnection between them. In order to maximize the capacity of the nation's entire transportation system it is critical to invest in the physical links in the process of exchanging cargo 
between the modes as well as in technology for an intermodal exchange of information. Containerization has been a key ingredient in the development of integrated intermodal transportation service. The introduction of standardized 20 (and later 40) foot containers brought forward the revolution in the movement of freight.

While containerization offers benefits even in single mode movements, one of its major benefits is that it makes the transfer of cargo between modes -- at ports, rail yards, and truck terminals - faster, easier, cheaper and safer. The use of the same equipment for sea, rail and truck operations has a considerable towards improving the efficiency of operations. However practical problems still exist, like the standards of ocean containers, which are 20,40 or 48 feet long. The different nature of the intermodal partnership is another important distinction between international and domestic intermodal activity one is cooperative, the other is competitive.

\section{INTERNATIONAL TRANSPORT FOR FOREIGN TRADE IN BULGARIA}

The positive effect of global trade liberalization in recent years is bringing forward increased flows of goods, capital, people and information. This is affecting the economic activities of Bulgaria and statistical data are showing augmentation of the total activity of international transport during 2011 - 2012 due to increasing the imports by $2.5 \%$ in 2012 compared to 2011 , and exports by $8.8 \%$ in 2012 compared to 2011. The rate of exports and imports of Bulgaria is constantly growing, with value levels of imports exceeding those of the exports (NSI, 2013).

\section{Table 2 Export, import and trading balance of Bulgaria by groups of generating trade partners'} countries

\begin{tabular}{|c|c|c|c|c|c|c|}
\hline \multirow[t]{3}{*}{ Sectors of SITC } & \multicolumn{3}{|c|}{ Export - FOB } & \multicolumn{3}{|c|}{ Import - CIF } \\
\hline & 2011 & 2012 & $\%$ & 2011 & 2012 & $\%$ \\
\hline & \multicolumn{2}{|c|}{ millions BGN } & & \multicolumn{2}{|c|}{ millions BGN } & \\
\hline Total & 39633.6 & 40622.9 & 2.5 & 45778.5 & 49793.7 & 8.8 \\
\hline EC states & 24652.1 & 23779.8 & -3.5 & 27183.7 & 29200.0 & 7.4 \\
\hline (OIC, OECD EAFT) & 14981.5 & 16843.1 & 12.4 & 18594.8 & 20593.7 & 10.7 \\
\hline
\end{tabular}

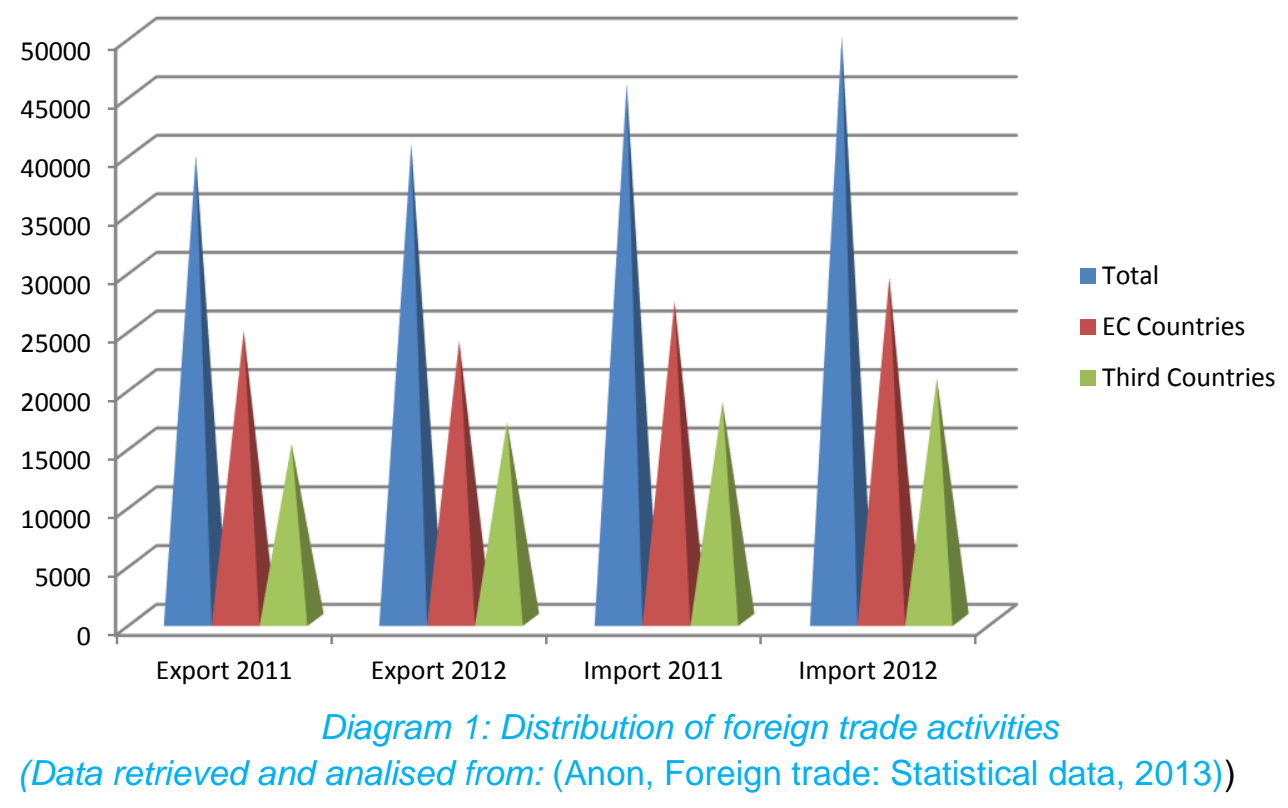


Following the above mentioned trend, the preliminary data for the first six months of 2013 are showing $6.6 \%$ increase of exports towards EU member states in comparison with the same period one year earlier, reaching 14.7 billion BGN. The major foreign trade partners of Bulgaria are situated in Germany, Italy and France (mediumsized distances) as well as Rumania and Greece (short distances, neighbouring countries), comprising $68.8 \%$ of the total value of the imports from EU.

The diagram 1 is a graphical representation of the data in the table 2. In July 2013, the exports towards EU increased by $7.9 \%$ compared with the same period of 2012, amounting at 2.4 billion BGN. Bulgaria's imports from the EU for the period January - July 2013 increased by 1.0\% compared with the same period of 2012, amounting at 17.3 billion BGN. The major foreign trade partners of Bulgaria were spotted to be again in Germany, Italy and France (medium-sized distance) as well as Romania and Greece (short distances, neighbouring countries), comprising $68.3 \%$ of the exports to the EU member states. In August 2013, the exports towards the EC countries increased by $20.2 \%$ compared with 2012 , amounting at 2.4 billion BGN.

The indirect conclusion drawn, based upon the analysis above is that road transport, with the opportunity of two-way loading is very suitable and corresponding to the real situation established in the field of Bulgarian foreign trade.

In Bulgarian export to EU, distributed according SITC (Standard International Trade Classification of UN), during the first six months of 2013 compared to the same period in 2012, the highest rate was registered in the sectors "Non-alcoholic and alcoholic drinks and tobacco" (28.5\%) as well as "Chemicals and related products "(24.0\%). The biggest decline (15.6\%) is registered in the sector "Mineral fuels, lubricants and related materials."

During the first six months of 2013, the imports of Bulgaria form the EU member states increased by $6.8 \%$ compared to the same period of 2012 , amounting at 2.8 billion BGN. The foreign trade balance of Bulgaria with the EU countries for the first six months of 2013 is negative. After elimination of transport and insurance costs from the import prices, the balance is still negative, amounting at 1780.4 million BGN. The largest percentage increase (by 11.4\%) was recorded in the sector "Greases, oils and waxes of animal or vegetable origin", while the largest decrease (by $4.7 \%$ ) occurred in the sector "Machinery, equipment and vehicles."

The widely spread use of road transport in the mutual trade with EC member state is proved by the consistent growing in the number of registered for public services freight vehicles. According to the National Institute of Statistics Reference Book 2013, in 2009 the number of registered road freight vehicles was 348,421 , reaching the number of 399,900 in 2012 . Besides the economic reason expressed above, the main reason for the increasing share of the road transport is seen in the technological adaptability for intracontinental transport services without transboarding, at a greater speed and shorter delivery terms in comparison with the rail transport (HSR being only available for passenger services). At the same time, for small consignments (above $10 \mathrm{~kg}$ ), the comparison with the offering of air freight transport is showing a direct service, at a comparatively high speed, lower and more transparent price.

European transport policy is aiming to promote the development of rail transport as an alternative of the road transport in order to reduce the negative impact and the pressure on the environment. It is entirely in unison with the necessities foreign trade flows of Bulgaria, bearing in mind the turnover with EU member states, but difficult to be applied taking into account the need of modernization of railway infrastructure and the necessity to improve the image of railways in front of the clients. The freight turnover distributed by modes of foreign trade transport could be followed by the data presented in the table 3. It explicitly shows that the largest general decline was registered in 2010 , followed by growth and reaching 2009 levels, thus presenting grounds to ascertain positive trend, despite the economic crisis. The outflow of customers from maritime transport can also be observed, providing a clear proof of the growing role of road transport. Also, the freight indicators and general data of surface freight transport are increasing, against decreasing of the indicators for water-borne transport. The comparison is based upon data from the third quarter of 2012 and 2013. 
The diagram 2 is a graphical representation of the data in the previous table. The quoted data show a steadily declining share of maritime as well as of air transport. The reasons for the decreasing interest in air transport can be high price (highest of all modes), strict requirements on the goods to be transported by plane, due to the increased terrorist risk, more regulations, etc.

Table 3 Freight over modes of international transport in Bulgarian foreign trade

(Data retrieved and analised from: (Anon, Transport, 2014))

\begin{tabular}{|c|c|c|c|c|}
\hline Mode of transport & 2009 & 2010 & 2011 & 2012 \\
\hline \multicolumn{5}{|c|}{ Freight carried (thousands tons) } \\
\hline Total & 97045 & 87416 & 101338 & 107184 \\
\hline Land transport & 87079 & 79441 & 95431 & 102155 \\
\hline Waterborne transport & 9947 & 7964 & 5899 & 5023 \\
\hline Air transport & 19 & 11 & 8 & 6 \\
\hline
\end{tabular}

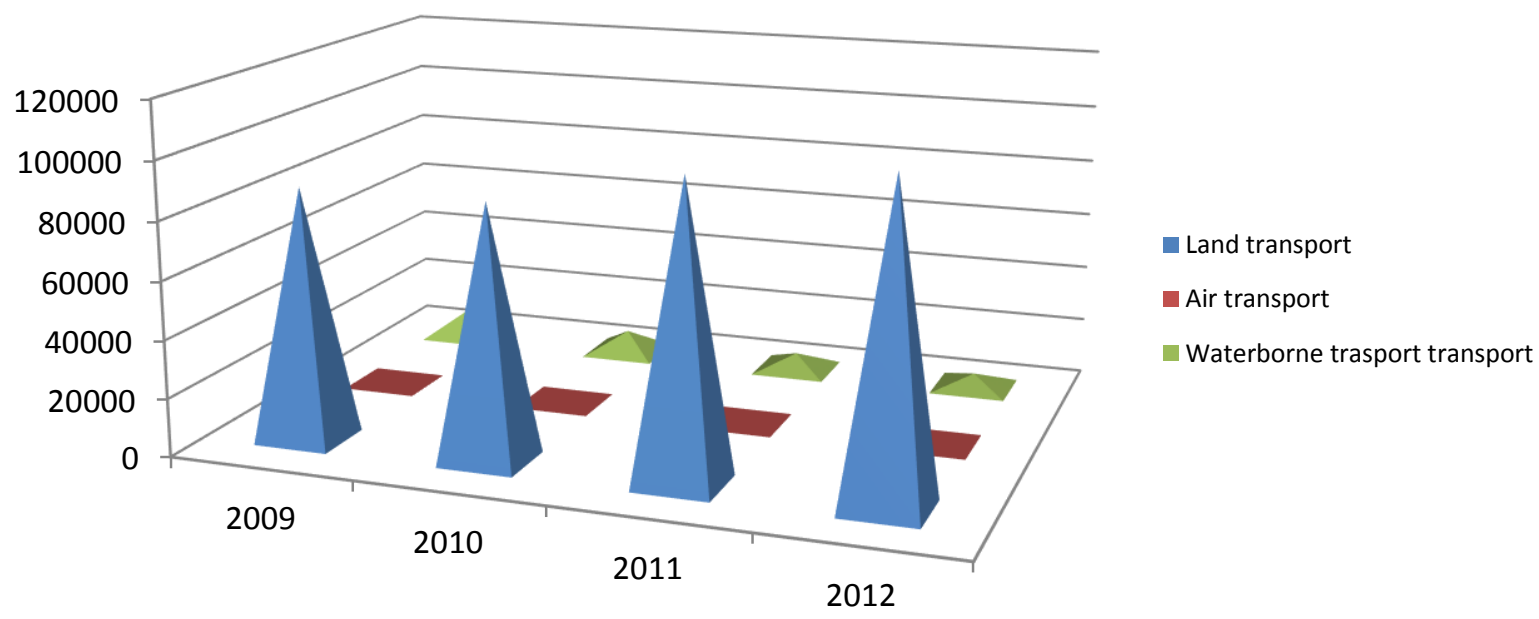

Diagram 2: Distribution of foreign trade cargo per modes of transport

The diagram 2 is a graphical representation of the data in the previous table. The quoted data show a steadily declining share of maritime as well as of air transport. The reasons for the decreasing interest in air transport can be high price (highest of all modes), strict requirements on the goods to be transported by plane, due to the increased terrorist risk, more regulations, etc.

According to the general opinion, the reduction of maritime transport share is mainly due to the crisis and the concentration of Bulgarian foreign trade within EC region (table 4). Long delivery times, considerdd to be another disadvantage of this mode transport is entirely unresponsive to the necessities of speedy deliveries in a time of intense competition.
The rapid recent development of Asian countries and the transformation of China and other countries in the region in leading manufacturing centers increased the demand for global and international long distance - haulage. The share of containerized general and bulk cargoes grew increasingly. However, the share of exports and imports between Bulgaria and China fell accordingly by $5.7 \%$ and $7.4 \%$ in 2013 in comparison to 2012. The data published in the National Institute of Statistics Reference Book 2013 as well as by the National Association of Bulgarian forwarders for the same period show decline in the carriage of goods by waterborne transport. Imports of freight by FCL from China and other Asian countries are reduced due to less economic efficiency from the slackened consumer 
turnover. On the other hand, the already shown increase in international trade from neighboring countries such as Turkey, Romania and other EC partners lessens the importance of maritime transport in Bulgarian foreign trade.

Table 4 Basic indicators of freight transport (2012 - 2013)

(Data retrieved and analised from: (Anon, Transport, 2014))

\begin{tabular}{|l|c|c|c|}
\hline Freight transport & 2012 & 2013 & $\%$ \\
\hline Surface transport - product flows (tons) \\
\hline Total (th. tons) & 27673.1 & 32815.8 & 118.6 \\
\hline Domestic freight & 19941.3 & 23219.2 & 116.4 \\
\hline International freight & 7731.8 & 9596.6 & 124.1 \\
\hline Surface transport - performance (tonkm) \\
\hline Total (mln. tonkm) & 6976.1 & 8903.3 & 127.6 \\
\hline Domestic freight & 1723.3 & 2203.6 & 127.9 \\
\hline International freight & 5252.8 & 6699.7 & 127.5 \\
\hline Water borne transport - product flows (tons) \\
\hline Total (th. tons) & 1395.1 & 666.1 & 47.7 \\
\hline Domestic freight & 16.6 & 8.2 & 49.4 \\
\hline International freight & 1378.5 & 657.9 & 47.7 \\
\hline Water borne transport - performance (tonkm) \\
\hline Total (mln. tonkm) & 3460.0 & 976.7 & 28.2 \\
\hline Domestic freight & 3.1 & 0.4 & 13.2 \\
\hline International freight & 3456.9 & 976.3 & 28.2 \\
\hline
\end{tabular}

Another important reason for the decrease of imports from Asian countries is considered to be the policy of protectionism in favor of European manufacturers by introducing temporary or permanent anti-dumping measures in the form of customs' charges on certain goods from China and other third countries (for example, for plastic sheet metal, bolts, seamless steel pipes, construction fibre glass nets, steel ropes, glass solar panels, etc.). Also, the sea freight rates are subject to increasing due to the remoteness between departure and destination points, port operations and container handling as well as some restrictions imposed upon maritime transport.

For the particular case of Bulgarian international transport, the Danube river transport is included in "water borne transport", thus providing other important reasons for decreasing its rate in the foreign trade servicing. The problems occurring with Danube river navigation, the shortcomings of the Danube port infrastructure are among the most important.

At the same time, data quoted by the Bulgarian Ministry of transport, IT and communications (MTITS, 2014) are contradicting, and reports show a different picture for the situation in maritime transport for 2013 (mediapool, 2014), meaning operation profit from the activities of National Company "Port Infrastructure", accounted for about 18 million BGN, with forecasted income amounting at 73 million BGN above the planned numbers; besides, investments for about 12 million BGN are reported, i.e. surpassing 2012 levels by 2 million BGN. The result of the leading ports'activities' analysis indicates that:

- Generally, in 2013 in the port of Varna was processed the nearly 11 million tons of cargo have been processed, and the expected financial result is amounting at 4,801 million 
BGN (i.e., an increase of over $16 \%$ is reported in comparison with 2012). conducted A priority investment in two mobile harbour cranes of over 9 million BGN has been made;

- For 2013, the port of Burgas has realized income of almost 20.6 million, which is $5.3 \%$ above the planned value. There are expectations for a substantial profit, above 6,88 than the planned value;

- There are sighns of decrease in the activity of the main river port Ruse. The processed quantities in 2013 are 595 thousand tons less than 2012 (i.e. there is a decrease by $20.5 \%$ ). At the same time the profit level is higher compared to 2012.

Another viewpoint over foreign trade transport services is provided by container traffic, which is rather unbalanced (about imports for 2010 there is an increase of about $17 \%$, then decline in 2011 ; about exports a $61 \%$ increase in 2010 and decline of $17 \%$ in 2011 ; the transit container traffic is increased $23 \%$ in 2010 and further with $61 \%$ in 2011), besides the mismatch of the data quoted by the National statistical institute of Bulgaria, and the indicates values in the government and business reports (on the page of the National Association of Bulgarian forwarders) for the same period.

Freight container traffic from and to Bulgaria at Thessaloniki port in 2012 shows almost two-fold increase compared to 2010 - (from 9068 to 16030 TEU), giving Bulgaria a share of $39.1 \%$ of the total container-traffic in the port. The growth continues in 2013 , and the traffic has increased about $29 \%$. A major problem in the provision of combined transport from the port is the connection to the railway network, which is expected to be resolved by the end of 2014 through an investment of 20 million Euros for modernization activities.

\section{Black Sea region turnover, Jan-Sept 2013 and 2012, TEU, full}

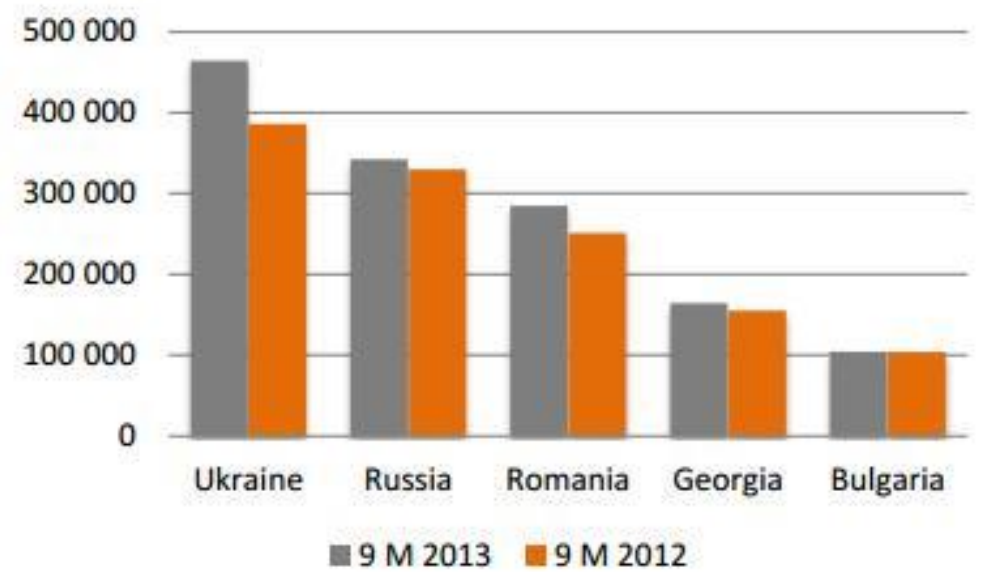

Diagram 4. Container transport of Bulgaria and other Black Sea Countries (Source: (Maritime, 2013) )

Overall increase in the cargo is available in the container terminals of the five Black Sea countries in 2013 , showing a growth of $10.95 \%$ compared to 2012, when 1,359,562 full TEU were processed. The largest increase was registered in Ukraine and Romania, while Bulgarian terminals initially reported decline, which was overcome by the end of the year. During the reported period, $61.66 \%$ of the processed containers were intended for the domestic market and $38.34 \%$ - for export, which is a sign of a misbalance. Exports from the five countries of the Black Sea have increased by
$17.76 \%$ compared to 2012 . The highest levels reported Ukraine (53.35\%) and Romania $(22.80 \%)$. Decline was registered in Russia, Georgia and Bulgaria. The import levels in the region have increased by $7.11 \%$, mainly due to Russia (13.02\%). The number of the processed containers in Bulgarian ports is the least compared to other countries of the Black Sea region: $7.67 \%$, followed by Georgia - $12.08 \%$, Romania - 20.94\%, Russia (only on the Black Sea) $-25.16 \%$ and Ukraine - $34.15 \%$. 


\section{INTELLIGENT TRANSPORT SYSTEMS}

IN THE FIELD OF THE BULGARIAN TRANSPORT SYSTEM

Directive 2010/40/EU for ITS (Directives, 2010), adopted on 07.07.2010 was the starting point towards new transport technologies aiming at raising the efficiency and competitiveness of the different modes of transport as well as the influence of the transport sector over the environment in general.

In the field of international transport and the Strategy for implementation of European system of railway traffic management (ERTMS), backed up by the National plan for the implementation $n$ there are activities for designing and building of dispatching centres and station computing systems for train traffic management. The first centralized management of the railway traffic on the line Plovdiv-Svilengrad -Turkish border was opened in 2012. The completed signalling and telecommunication systems allow a maximum designed speed of $160 \mathrm{~km} / \mathrm{h}$. The construction project also comprises the introduction of systems for remote control SCADA.

Providing and maintaining high levels of quality of air navigation services in the context of the Single European Sky, in terms of improving the organization and management of air transport in 2012 amendments has been achieved through the route network and scheduled arrivals and departures in accordance with the plans of the European Organisation for the Safety of Air Navigation (EUROCONTROL) . A functional airspace block DANUBE FAB was launched in 2012, through which Bulgaria and Romania together optimize the capacity of their airspace, increase cost-efficiency, improve or maintain the same level of safety and ensure environmental sustainability in the context of the increasing air traffic.

In the field of maritime transport for almost 5 years an Obligatory System for faraway detection and following of ships is functioning, through which the EU integrates all data about national flag carries' ships. As successful is valued the functioning of the Bulgarian part of the European system for shipping date exchange SafeSeaNet. Under a contract with the European Agency of safety at sea the access to the new information system STIRES, upgrading SafeSeaNet is ensured.

In the field of river navigation the project "Information system for traffic management of vessels on the Danube" has been worked upon, namely VTMIS, stage III.

\section{CONCLUSION}

The data quoted in table 2 show a tendency of decreasing the share of waterborne as well as air cargo transport. Among the reasons for the constraints in the use of air transport is considered to be the comparatively higher price than the other modes of transportations as well as increasing the regulations for carrying of goods by air (due to safety and security procedures).

On the other hand, the economic crisis has highly affected the maritime borne freight leading to shrinking the circle of foreign trade partnerships mainly within EC, i.e. regionalization versus globalization of trade relations. For example, there is a decrease in the import of containers (FCL) from China and other Asian countries and on the other hand an increase in the trading volumes from countries such as Turkey, Rumania, etc. Another shortcoming is the prolonged delivery terms.

The liberalized EC markets lift the burden over the prices of different commodities and the competitiveness is further increased by the decreased transportation costs due to the short distances and delivery terms. Also, the turnover of capital invested in big consignments is accelerated due to the speedy deliveries. Hence, in contradiction to the EC transportation policy, the efficiency of the road transport in foreign trade is further revealed.

The situation of North American and Asian companies' headquarters in Western Europe, FCL imports, stowage and distribution for partners in EC member states allows the facilitation of the global trade relations thus increasing the efficiency of foreign trade. The aggregation of the ordered deliveries is leading to a further decreasing of transportations costs. The market of Bulgaria, being comparatively small is highly profiting from the option deliveries of goods 
through the headquarters of partners situated outside Europe.

In conclusion, due to the high competitiveness of the road haulage on short and medium-sized distances it is the most widely used in the international exchange of goods in the country and this tendency is revealed by the current statistical data in Bulgaria. The option air cargo is still limited due to the comparatively higher prices of transportation.

Advanced technologies, particularly IT, also have a great impact on physical distribution of freight. It has heightened competition by providing tools for more focused operations as well as new strategic partnerships within the supply chains.

\section{WORKS CITED}

Anon. (2013). Foreign trade: Statistical data. Retrieved from National Statistical Institute of Bulgaria: http://www.nsi.bg/en/search/node/foreign\%20trade

Anon. (2014). Transport. Retrieved from National Statistical Institute of Bulgaria: http://www.nsi.bg/bg/content/1704/\%D1\%82\%D1\%80\%D0\%B0\%D0\%BD\%D1\%81\%D0\%BF \%D0\%BE\%D1\%80\%D1\%82

Anon. (2014). Transport. Retrieved from National Statistical Institute of Bulgaria: http://www.nsi.bg/bg/content/1704/\%D1\%82\%D1\%80\%D0\%B0\%D0\%BD\%D1\%81\%D0\%BF \%D0\%BE\%D1\%80\%D1\%82

Directives. (2010, 08 06). Directive 2010/40/EU of the European parliament and of the council of 7 July 2010. Official Journal of the European Union, L207/1-13.

Euroepan Commission. (2014). Statistics. Retrieved from Trade: http://ec.europa.eu/trade/policy/countries-and-regions/statistics/

Filipova, I. (2012, 01 11). Evropa okonchatelno otvori pazara za bulgarskite prevozvachi. Retrieved from Kapital:

http://www.capital.bg/biznes/kompanii/2012/01/11/1743026_evropa_okonchatelno_otvori_paz ara_za_bulgarskite/

Maritime. (2013, 11 20). Chernomorski konteiineren rastezh $v$ pet strani (analiz). Retrieved from Maritime.bg:

http://www.maritime.bg/2013/11/20/\%D1\%87\%D0\%B5\%D1\%80\%D0\%BD\%D0\%BE\%D0\%BC \%D0\%BE\%D1\%80\%D1\%81\%D0\%BA\%D0\%B8-

\%D0\%BA\%D0\%BE\%D0\%BD\%D1\%82\%D0\%B5\%D0\%B9\%D0\%BD\%D0\%B5\%D1\%80\%D0

\%B5\%D0\%BD-\%D1\%80\%D0\%B0\%D1\%81\%D1\%82\%D0\%B5\%D0\%B6-\%D0\%B2-

\%D0\%BF\%D0\%B5\%D1\%82/

mediapool. (2014, 01 16). Morskite pristanishta s rekorden oborot, rechnite na minus. Retrieved from mediapool.bg: http://www.mediapool.bg/morskite-pristanishta-s-rekorden-oborot-rechnite-naminus-news215686.html

MTITS. (2014). Retrieved from Ministry of transport, information technology and communications: http://www.mtitc.government.bg/

NSI. (2013, 05 07). Foreign Trade. Retrieved from National Statistical Institute of Bulgaria. : http://ftrade.nsi.bg/portal/page?_pageid=34,1\&_dad=portal\&_schema=PORTAL

OECD. (2014). Transport and foreign trade stattistics. Retrieved from OECD: http://www.oecd.org/std/its/itcsinternationaltradebycommoditystatistics.htm / 
Statistics Brief. $(2013,12)$. Trends in the Transport Sector. Retrieved from International Transport Forum: $\quad$ http://www.internationaltransportforum.org/statistics/StatBrief/2013-12-TrendsPerspective.pdf

Received for publication: $\quad 31.01 .2014$

Revision received: $\quad 17.05 .2014$

Accepted for publication: $\quad$ 23.06.2014

How to cite this article?

Style - APA Sixth Edition

Kirova, A. (2014, 07 15). The role of the international transport in foreign trade realization. (Z. Čekerevac, Ed.) MEST Journal, 2(2), 74-85. doi:10.12709/mest.02.02.02.08

Style - Chicago Fifteenth Edition:

Kirova, Antoaneta. 2014. "The role of the international transport in foreign trade realization." Edited by Zoran Čekerevac. MEST Journal (MESTE) 2 (2): 74-85. doi:10.12709/mest.02.02.02.08.

Style - GOST Name Sort:

Kirova Antoaneta The role of the international transport in foreign trade realization [Journal] // MEST Journal / ed. Čekerevac Zoran. - Belgrade : MESTE, 07 15, 2014. - 2 : Vol. 2. - pp. 74-85.

Style - Harvard Anglia:

Kirova, A., 2014. The role of the international transport in foreign trade realization. MEST Journal, 15 07, 2(2), pp. 74-85.

Style - ISO 690 Numerical Reference:

The role of the international transport in foreign trade realization. Kirova, Antoaneta. [ed.] Zoran Čekerevac. 2, Belgrade : MESTE, 07 15, 2014, MEST Journal, Vol. 2, pp. 74-85. 